\title{
I-CLIP: Improved Stratification of Advanced Hepatocellular Carcinoma Patients by Integrating Plasma IGF-1 into CLIP Score
}

\author{
Ahmed O. Kaseb ${ }^{a}$ James L. Abbruzzese ${ }^{a} \quad$ Jean-Nicolas Vauthey ${ }^{b}$ \\ Thomas A. Aloia ${ }^{b}$ Eddie K. Abdalla ${ }^{b}$ Manal M. Hassan ${ }^{a} \quad$ E. Lin ${ }^{c}$ Lianchun Xiao $^{c}$ \\ Adel S. El-Deeb ${ }^{a}$ Asif Rashid ${ }^{d}$ Jeffrey S. Morris ${ }^{c}$

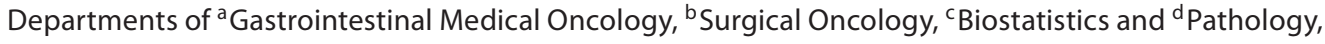 \\ The University of Texas, MD Anderson Cancer Center, Houston, Tex., USA
}

\section{Key Words}

Cancer of the Liver Italian Program (CLIP) score • Chronic

liver disease $\cdot$ Hepatocellular carcinoma $\cdot$ IGF-1

\begin{abstract}
Objective: Improving the prognostic stratification of unresectable hepatocellular carcinoma (HCC) patients is critically needed. Since patients' survival is closely linked to the severity of the underlying liver disease, and insulin-like growth factor-1 (IGF-1) is produced predominantly in the liver, we hypothesized that IGF-1 may correlate with patients' survival and hence improve the prognostic ability of the Cancer of the Liver Italian Program (CLIP) score. Methods: Baseline plasma IGF-1 and clinicopathologic parameters were available from 288 patients. Multivariate Cox regression models, Kaplan-Meier curves, and the log-rank test were applied. Recursive partitioning was used to determine the optimal cut point for IGF-1 using training/validation samples. Prognostic ability of the I-CLIP (I = IGF) was compared to CLIP using Cindex. Results: IGF-1 significantly correlated with the clinicopathologic features. With an optimal IGF-1 cut point of $26 \mathrm{ng} / \mathrm{ml}$, the overall survival of patients with IGF-1 $>26$ was 17.7 months (95\% Cl 13.6-22.8), and with IGF-1 $\leq 26$ was 5.8
\end{abstract}

months (95\% Cl 4.0-12.5), $\mathrm{p}<0.0001$. The concordance probabilities for CLIP and I-CLIP were 0.7037 and 0.7096, respectively $(p<0.0001)$. Conclusions: Our preliminary results indicate that I-CLIP significantly improved prognostic stratification of patients with advanced HCC. However, independent validation of our study is warranted.

Copyright $\odot 2011$ S. Karger AG, Basel

\section{Introduction}

Hepatocellular carcinoma (HCC) develops as a consequence of underlying chronic liver disease (CLD), most commonly cirrhosis due to viral hepatitis. Therefore, the majority of patients with HCC suffer from two co-existing competing causes of morbidity and mortality, the severity of their CLD and the HCC tumor stage. This syndrome of the two-disease state directly affects survival, which in turn affects patients' prognostic stratification and treatment decisions in clinical trials and in clinical practice. Therefore, most of the HCC staging systems include a combination of variables related to the tumor stage and the status of the CLD. However, several challenges face the clinical utility of these staging systems. First, their perfor-

\section{KARGER}

(C) 2011 S. Karger AG, Basel

Fax +41613061234 E-Mail karger@karger.ch www.karger.com www.karger.com/ocl
Ahmed O. Kaseb, MD

Department of Gastrointestinal Medical Oncology, Unit 426

The University of Texas, MD Anderson Cancer Center

1515 Holcombe Blvd., Houston, TX 77030 (USA)

Tel. +1 713792 2828, E-Mail akaseb@ mdanderson.org 
mance is highly variable because they were developed from different patient populations, surgical and nonsurgical, and they depend on many factors including patient demographics. Secondly, they lack the integration of new biologic biomarkers that correlate with the tumor parameters and with the severity of the underlying CLD. In this context, non-invasive means of obtaining those markers is essential, given the challenges in obtaining tissue samples in patients with cirrhosis and coagulation disorders that put HCC patients at risk for complications following needle biopsies.

The Cancer of the Liver Italian Program (CLIP) score [1] and the Barcelona Clinic Liver Cancer (BCLC) staging system [2] are among the most commonly used HCC prognostic systems to stratify patients on clinical trials in the Western world. The BCLC staging system [2] is endorsed by the American Association for the Study of Liver Diseases (AASLD) and the European Association for the Study of Liver Diseases (EASL) clinical practice guidelines $[3,4]$. Notably, our most recent publication compared the prognostic accuracy of the CLIP score to that of the BCLC staging in our patient population using the $\mathrm{C}$-index, and found that the concordance probabilities for BCLC and CLIP were 0.65 and 0.70 , respectively [5]. Using U-statistics, the difference was significant and the $\mathrm{p}$ value was 0.007 . Thus, these results indicate that the CLIP scoring system better predicted survival than BCLC staging in our patient population.

The CLIP score is a prognostic system that assigns points for the Child-Pugh score, tumor morphology (solitary, $\leq 50 \%$ of the liver, massive), serum $\alpha$-fetoprotein (AFP), and presence or absence of portal vein thrombus [1]. Notably, many studies validated the use of CLIP in HCC patients [6-15]. Furthermore, recent studies, including one of our patient population [5], evaluated the predictive accuracy of different HCC staging systems and showed that the CLIP score was more predictive than BCLC in the studied patient populations, which included a significant number of patients with advanced HCC [5, $16,17]$. However, the two systems are conceptually different and cannot be directly compared. The BCLC staging system was originally designed as a treatment allocation algorithm and subsequently evolved as one of the standard systems to stage HCC patients, whereas the CLIP score is a prognostic system that was designed to stratify patients according to their expected survival. In addition, several studies indicated that about $80 \%$ of the CLIP patient population is classified as a CLIP score of $0-3[5,9$, 10]; therefore, there is an unmet need to improve the accuracy of CLIP score stratification.
Insulin-like growth factor-1 (IGF-1) is a hormone that is predominantly synthesized in the liver [18]. Therefore, low circulating IGF-1 levels have been found to be associated with CLD, such as steatosis, chronic hepatitis C, cirrhosis, non-alcoholic steatohepatitis, and HCC [19-25]. Collectively, these data suggest that circulating levels of IGF-1 may reflect the synthetic function of the liver and correlate with patients' advanced CLD status, which directly affects the survival of patients with HCC independent of their tumor stage.

However, evaluating the role of IGF-1 in predicting survival of patients with HCC and in refining their prognostic stratification has not been studied yet. Therefore, we hypothesized that baseline plasma levels of IGF-1 will correlate with the clinicopathologic features and survival of patients with HCC and hence may improve the predictive ability of the CLIP score for HCC.

\section{Patients and Methods}

\section{Study Population}

After obtaining MD Anderson's Institutional Review Board approval and patients' informed consent, we enrolled new patients with pathologically proven HCC. We excluded patients with concurrent presence or history of other malignancies, including other types of primary liver cancer (such as bile duct cancers or fibrolamellar HCC). Patients' medical records were reviewed for baseline clinical, laboratory, pathologic, staging, and radiologic features. We recruited 394 eligible patients; baseline plasma samples were available for 288 only who returned for blood samples collection. There were no significant differences between our study population and patients who were missed, either in their age, race, and gender, hepatitis status, diabetes history, alcohol consumption, smoking, Child-Pugh score, cirrhosis; pathological cellular differentiation; serum albumin, or CLIP scoring. However, patients without blood samples had a tendency to have multinodular tumor, higher AFP levels, portal vein thrombosis, and higher incidence of tumor size involving $<50 \%$ of the liver. Overall survival time was calculated to reflect the time between diagnosis and last follow-up visit or death.

\section{Baseline Plasma IGF-1}

Baseline venous blood samples (3-5 $\mathrm{ml}$ of the whole blood) were collected, anticoagulated by ethylenediaminetetraacetic acid (EDTA) and centrifuged at $4^{\circ} \mathrm{C}$ and 3,000 r.p.m. for $15 \mathrm{~min}$. The plasma samples were then removed, aliquoted, and snap frozen at $-20^{\circ} \mathrm{C}$. IGF-1 was tested using ELISA (Quantikine Human IGF-1 Immunoassay ELISA Kit; R\&D Systems, Minneapolis, Minn., USA). The plasma biomarker level was determined from a standard curve generated for each of the sample sets assayed after duplicate measurements were made.

\section{Statistical Analysis}

We used Cox regression to assess factors associated with overall survival, and Wilcoxon rank sum test to study the correlation 
between baseline IGF-1 and various clinical characteristics and staging systems. To identify an optimal IGF-1 cut point, recursive partitioning methodology [26] was used to split the data randomly into training (2/3) and validation (test) (1/3) sets. We used the training set to find the optimal cut point maximizing the survival difference between the low and high IGF-1 groups, and then validated the cut point by fitting a Cox regression model to the dichotomized IGF-1 value on the test data. We repeated this methodology using 20 different random splits. Next, we fitted the multivariable Cox regression models including IGF-1, dichotomized at the optimal cut point, and the variables within the CLIP system, to evaluate whether IGF-1 was an independent prognostic factor after adjusting for the CLIP variables. Finally, the median survival was computed in each I-CLIP (I = IGF) group $(0,1,2,3$, 4 , and $5+$ ) and the groups were compared using log-rank tests, to assess the performance of the I-CLIP in comparison to the CLIP. The sign test was used to assess whether the IGF-1-low groups tended to have shorter median survival within the CLIP and ICLIP groups than IGF-1-high groups. The prognostic ability of the CLIP and I-CLIP was compared using a C-index test, with secondary analyses done to compute a partial C-index analysis, which computed the C-index using only patients whose class status changed between CLIP and I-CLIP.

\section{Results}

\section{Patient Characteristics}

For the entire cohort of 288 patients, the median overall survival was 13.8 months, (95\% CI 11.7-17.3). Baseline patients' characteristics are shown in table 1 . The Cox regression models indicated that vascular invasion, tumor differentiation and nodularity, high serum level of AFP, bilirubin, alanine transaminase (ALT), aspartate transaminase (AST), presence of cirrhosis, a Child-Pugh score of $B$ or $C$, and extrahepatic metastasis were all significant predictors of shorter overall survival.

\section{Prognostic Factors of Survival in Our Patient \\ Population}

Most recently, we reported that the discriminative ability of the CLIP score was better than that of the BCLC staging system in our patient population [5]. In that study, we applied a multivariable Cox regression model to our data including the factors contained in the CLIP score to validate the CLIP scoring system in our patient population. Only 285 patients were included because AFP values were missing for 3 patients. The study hazard ratios (HRs) were very close to the HRs reported in the original CLIP paper [1]. The CLIP score stratified our patients very effectively into different prognostic categories $(\mathrm{p}<$ 0.0001).
Table 1. Patient Characteristics

\begin{tabular}{|c|c|}
\hline Variable & $\begin{array}{l}\text { Patients, } \mathrm{n}(\%) \\
(\mathrm{n}=288)\end{array}$ \\
\hline \multicolumn{2}{|l|}{ Age } \\
\hline$<60$ years & $111(38.5)$ \\
\hline$\geq 60$ years & $177(61.5)$ \\
\hline \multicolumn{2}{|l|}{ Gender } \\
\hline Female & 89 (30.9) \\
\hline Male & $199(69.1)$ \\
\hline \multicolumn{2}{|l|}{ Serum AFP level } \\
\hline$<400 \mathrm{ng} / \mathrm{ml}$ & $199(69.1)$ \\
\hline$\geq 400 \mathrm{ng} / \mathrm{ml}$ & $86(29.8)$ \\
\hline Missing & $3(1.0)$ \\
\hline \multicolumn{2}{|c|}{ Tumor differentiation } \\
\hline Well & $112(38.9)$ \\
\hline Moderate & $95(33.0)$ \\
\hline Poor & $50(17.4)$ \\
\hline Unknown & $31(10.8)$ \\
\hline \multicolumn{2}{|l|}{ Tumor size } \\
\hline$\leq 50 \%$ of liver & $191(66.3)$ \\
\hline$>50 \%$ of liver & $97(33.7)$ \\
\hline \multicolumn{2}{|l|}{ Vascular invasion } \\
\hline Yes & $53(18.4)$ \\
\hline No & $235(81.6)$ \\
\hline \multicolumn{2}{|l|}{ Distant metastasis } \\
\hline Yes & $60(20.8)$ \\
\hline No & $228(79.2)$ \\
\hline \multicolumn{2}{|c|}{ Hepatitis infection status } \\
\hline $\mathrm{HBV}$ & $38(13.2)$ \\
\hline $\mathrm{HCV}$ & $60(20.8)$ \\
\hline $\mathrm{HCV}+\mathrm{HBV}$ & $27(9.4)$ \\
\hline None & $163(56.6)$ \\
\hline \multicolumn{2}{|l|}{ Nodularity } \\
\hline Uninodular & $105(36.5)$ \\
\hline Multinodular & $183(63.5)$ \\
\hline \multicolumn{2}{|c|}{ Lymph node involvement } \\
\hline Yes & $122(42.4)$ \\
\hline No & $166(57.6)$ \\
\hline \multicolumn{2}{|l|}{ Bilirubin level } \\
\hline$\leq 1.6 \mathrm{mg} / \mathrm{dl}$ & $260(90.3)$ \\
\hline$>1.6 \mathrm{mg} / \mathrm{dl}$ & $28(9.7)$ \\
\hline \multicolumn{2}{|l|}{ Cirrhosis } \\
\hline Yes & $173(60.1)$ \\
\hline No & $115(39.9)$ \\
\hline \multicolumn{2}{|l|}{ Child-Pugh class } \\
\hline $\mathrm{A}$ & $206(71.5)$ \\
\hline $\mathrm{B}$ & $76(26.4)$ \\
\hline $\mathrm{C}$ & $6(2.1)$ \\
\hline
\end{tabular}

$\mathrm{HBV}=$ Hepatitis B virus; $\mathrm{HCV}=$ hepatitis $\mathrm{C}$ virus.

Reprinted with permission from Kaseb et al. [5]. (c) 2011 American Cancer Society, Inc. 
Table 2. Correlations between plasma IGF-1 level and patient characteristics by the Wilcoxon rank-sum test

\begin{tabular}{|c|c|c|c|}
\hline Patient characteristic & $\begin{array}{l}\text { Patients } \\
\mathrm{n}(\%) \\
(\mathrm{n}=288)\end{array}$ & $\begin{array}{l}\text { Plasma IGF-1 } \\
\text { level }(\mathrm{ng} / \mathrm{ml}) \\
\text { mean } \pm \mathrm{SE}\end{array}$ & $\mathrm{p}$ \\
\hline \multicolumn{4}{|l|}{ Age } \\
\hline$<60$ years & $111(38.5)$ & $59.37 \pm 45.35$ & \multirow[t]{2}{*}{0.07} \\
\hline$\geq 60$ years & $177(61.5)$ & $50.95 \pm 35.57$ & \\
\hline \multicolumn{4}{|l|}{ Race } \\
\hline Non-White & $89(30.9)$ & $53.51 \pm 42.82$ & \multirow[t]{2}{*}{0.84} \\
\hline White & $199(69.1)$ & $49.55 \pm 35.42$ & \\
\hline \multicolumn{4}{|l|}{ Gender } \\
\hline Female & $89(30.9)$ & $59.16 \pm 42.87$ & \multirow[t]{2}{*}{0.14} \\
\hline Male & $199(69.1)$ & $51.97 \pm 35.17$ & \\
\hline \multicolumn{4}{|c|}{ Hepatitis infection status } \\
\hline HBV & $38(13.2)$ & $56.07 \pm 49.16$ & \multirow{4}{*}{0.047} \\
\hline $\mathrm{HCV}$ & $60(20.8)$ & $52.33 \pm 32.27$ & \\
\hline $\mathrm{HBV}+\mathrm{HCV}$ & $27(9.4)$ & $35.77 \pm 22.24$ & \\
\hline None & $163(56.6)$ & $57.50 \pm 38.07$ & \\
\hline \multicolumn{4}{|l|}{ Serum AFP level } \\
\hline$<400 \mathrm{ng} / \mathrm{ml}$ & $199(69.1)$ & $56.46 \pm 36.03$ & \multirow[t]{3}{*}{0.08} \\
\hline$\geq 400 \mathrm{ng} / \mathrm{ml}$ & $86(29.9)$ & $49.62 \pm 41.84$ & \\
\hline Unknown & $3(1.0)$ & & \\
\hline \multicolumn{4}{|l|}{ Tumor differentiation } \\
\hline Well & $112(38.9)$ & $55.23 \pm 36.47$ & \multirow[t]{4}{*}{0.63} \\
\hline Moderate & $95(33.0)$ & $56.63 \pm 38.19$ & \\
\hline Poor & $50(17.4)$ & $48.29 \pm 38.48$ & \\
\hline Unknown & $31(10.8)$ & $52.51 \pm 40.83$ & \\
\hline \multicolumn{4}{|l|}{ Tumor nodularity } \\
\hline Uninodular & $105(36.5)$ & $63.25 \pm 42.01$ & \multirow[t]{2}{*}{0.002} \\
\hline Multinodular & $183(63.5)$ & $49.00 \pm 34.19$ & \\
\hline \multicolumn{4}{|l|}{ Tumor size } \\
\hline$\leq 50 \%$ of the liver & $191(66.3)$ & $60.11 \pm 41.33$ & \multirow[t]{2}{*}{0.0002} \\
\hline$>50 \%$ of the liver & $97(33.7)$ & $42.54 \pm 26.10$ & \\
\hline \multicolumn{4}{|l|}{ Vascular invasion } \\
\hline No & $235(81.6)$ & $56.73 \pm 39.40$ & \multirow[t]{2}{*}{0.016} \\
\hline Yes & $53(18.4)$ & $42.94 \pm 27.19$ & \\
\hline \multicolumn{4}{|c|}{ Lymph node involvement } \\
\hline No & $166(57.6)$ & $53.79 \pm 33.58$ & \multirow[t]{2}{*}{0.83} \\
\hline Yes & $122(42.4)$ & $54.75 \pm 49.19$ & \\
\hline Distant metastasis & & & \\
\hline No & $228(79.2)$ & $54.40 \pm 38.09$ & 0.85 \\
\hline Yes & $60(20.8)$ & $53.39 \pm 36.93$ & \\
\hline Bilirubin level & & & \\
\hline$\leq 1.6 \mathrm{mg} / \mathrm{dl}$ & $260(90.3)$ & $56.84 \pm 38.03$ & 0.0003 \\
\hline$>1.6 \mathrm{mg} / \mathrm{dl}$ & $28(9.7)$ & $29.63 \pm 24.73$ & \\
\hline Child-Pugh class & & & \\
\hline A & $206(71.5)$ & $59.05 \pm 38.62$ & 0.0021 \\
\hline B & $76(26.4)$ & $42.49 \pm 32.60$ & \\
\hline C & $6(2.1)$ & $35.77 \pm 37.38$ & \\
\hline ALT level & & & \\
\hline$\leq 40 \mathrm{U} / \mathrm{l}$ & $134(46.5)$ & $59.71 \pm 43.40$ & 0.02 \\
\hline$>40 \mathrm{U} / \mathrm{l}$ & $153(53.1)$ & $49.39 \pm 31.59$ & \\
\hline Unknown & $1(0.4)$ & & \\
\hline AST level & & & \\
\hline$\leq 45 \mathrm{U} / \mathrm{l}$ & $88(30.6)$ & $68.54 \pm 42.18$ & $<0.0001$ \\
\hline$>45 \mathrm{U} / 1$ & $179(62.2)$ & $47.26 \pm 33.68$ & \\
\hline Unknown & $21(7.3)$ & $53.20 \pm 36.31$ & \\
\hline
\end{tabular}

$\mathrm{HBV}=$ Hepatitis $\mathrm{B}$ virus; $\mathrm{HCV}=$ hepatitis $\mathrm{C}$ virus; $\mathrm{SE}=$ standard error.
Table 3. Univariate Cox proportional hazards regression analysis

\begin{tabular}{|c|c|c|c|}
\hline Predictor & HR & $\begin{array}{l}95 \% \mathrm{CI} \\
\text { of HR }\end{array}$ & $\mathrm{p}$ \\
\hline Gender (male vs. female) & 1.44 & $1.06-1.96$ & 0.018 \\
\hline Age ( $>60$ vs. $\leq 60$ years $)$ & 0.88 & $0.66-1.16$ & 0.351 \\
\hline Race (White vs. non-White) & 0.75 & $0.56-1.00$ & 0.051 \\
\hline \multicolumn{4}{|l|}{ Hepatitis virus infection } \\
\hline No infection vs. HBV + HCV & 0.51 & $0.32-0.80$ & 0.004 \\
\hline HBV alone vs. HBV + HCV & 0.76 & $0.44-1.32$ & 0.334 \\
\hline HCV alone vs. HBV + HCV & 0.72 & $0.43-1.18$ & 0.192 \\
\hline Tumor differential (poor vs. other) & 1.63 & $1.15-2.31$ & 0.006 \\
\hline $\operatorname{AFP}(\geq 400$ vs. $<400 \mathrm{ng} / \mathrm{ml})$ & 2.26 & $1.69-3.02$ & $<0.0001$ \\
\hline Tumor nodularity (multi vs. uni) & 2.28 & $1.68-3.11$ & $<0.0001$ \\
\hline Tumor size ( $>50$ vs. $\leq 50 \%$ ) & 2.92 & $2.19-3.90$ & $<0.0001$ \\
\hline Vascular invasive (yes vs. no) & 2.65 & $1.90-3.70$ & $<0.0001$ \\
\hline Metastasis (yes vs. no) & 1.76 & $1.27-2.45$ & 0.001 \\
\hline \multicolumn{4}{|l|}{ Lymph node involvement } \\
\hline (yes vs. no) & 1.82 & $1.38-2.40$ & $<0.0001$ \\
\hline Bilirubin (>1.6 vs. $\leq 1.6 \mathrm{ng} / \mathrm{ml})$ & 2.74 & $1.78-4.22$ & $<0.0001$ \\
\hline Serum AST (>45 vs. $\leq 45 \mathrm{U} / \mathrm{l}$ ) & 2.17 & $1.57-3.00$ & $<0.0001$ \\
\hline Serum ALT ( $>40$ vs. $\leq 40 \mathrm{U} / \mathrm{l}$ ) & 1.77 & $1.34-2.34$ & $<0.0001$ \\
\hline Cirrhosis (yes vs. no) & 1.35 & $1.02-1.79$ & 0.036 \\
\hline \multicolumn{4}{|l|}{ Treatment } \\
\hline Chemotherapy vs. none & 0.56 & $0.38-0.84$ & 0.0047 \\
\hline Surgery vs. none & 0.19 & $0.12-0.31$ & $<0.0001$ \\
\hline Chemoembolization vs. none & 0.38 & $0.22-0.67$ & 0.0008 \\
\hline IGF-1 (<26 vs. $\geq 26$ ng/ml) & 2.06 & $1.5-2.81$ & $<0.0001$ \\
\hline
\end{tabular}

Reprinted with permission from Kaseb et al. [5]. (c) 2011 American Cancer Society, Inc.

Table 4. Multivariable Cox proportional hazards model for ICLIP: CLIP score variables + IGF-1 dichotomized by $26 \mathrm{ng} / \mathrm{ml}$

\begin{tabular}{llll}
\hline I-CLIP score variables & HR & $\begin{array}{l}95 \% \text { CI } \\
\text { of HR }\end{array}$ & $\mathrm{p}$ \\
\hline $\begin{array}{l}\text { Child-Pugh } \\
\text { B vs. A }\end{array}$ & 1.69 & $1.22-2.33$ & 0.001 \\
$\quad$ C vs. A & 2.84 & $1.12-7.22$ & 0.03 \\
$\begin{array}{l}\text { Tumor morphology } \\
\quad \text { vs. } 0\end{array}$ & 1.67 & $1.15-2.43$ & 0.007 \\
$\quad 2$ vs. 0 & 3.65 & $2.46-5.42$ & $<0.0001$ \\
$\begin{array}{l}\text { AFP } \\
\quad \geq 400 \text { vs. }<400 \mathrm{ng} / \mathrm{ml}\end{array}$ & 1.72 & $1.26-2.34$ & 0.0006 \\
$\begin{array}{l}\text { Portal thrombosis } \\
\quad \text { yes vs. no }\end{array}$ & 1.41 & $0.89-2.23$ & 0.14 \\
$\begin{array}{l}\text { IGF-1 } \\
\quad 26 \text { vs. }>26 \mathrm{ng} / \mathrm{ml}\end{array}$ & 1.53 & $1.09-2.13$ & 0.01 \\
\hline
\end{tabular}


Baseline Plasma Levels of IGF-1 as an Independent Prognostic Factor

Table 2 describes the correlations between plasma IGF-1 level and patient characteristics by the Wilcoxon rank-sum test. Univariate Cox regression analyses showed that baseline plasma IGF-1 level was most significantly associated with Child-Pugh score, bilirubin, AST levels, tumor size and nodularity, and vascular invasion; however, the strongest association was with AST level $(\mathrm{p}<0.0001$; table 3$)$.

Identifying the Optimal Cut Points of Plasma IGF-1 in Our Patient Population

We applied the recursive partitioning test to randomly selected training/test sets to find the optimal single cut point for baseline IGF-1 in terms of predicting survival. We found that 8 of the 20 sets found roughly the same optimal cut points of $26 \mathrm{ng} / \mathrm{ml}$. Our results suggest that patients with low IGF-1 $(<26 \mathrm{ng} / \mathrm{ml})$ had shorter median overall survival. When 'low IGF-1' was considered in a univariate Cox regression model fit to the entire data set, this effect was highly significant $(\mathrm{p}<0.0001$; HR 2.06; 95\% CI 1.50-2.81). The median overall survival time estimate for patients with IGF-1 >26 was 17.7 months (95\% CI 13.6-22.8), and for IGF-1 $\leq 26$ was 5.8 months (95\% CI $4.0-12.5 ; \mathrm{p}<0.0001$; see Kaplan-Meier estimates; fig. 1).

\section{Constructing the I-CLIP Scoring System}

Our current multivariate analysis, using the dichotomized value of IGF-1, indicated that IGF-1 was a significant independent prognostic factor for overall survival, even after adjusting for CLIP parameters $(\mathrm{p}=0.01$; HR 1.53; 95\% CI 1.09-2.13; table 4). We also observed that IGF-1 incorporation in the CLIP score did not alter the HRs for the CLIP parameters.

Baseline Plasma IGF-1 Separates High-and Low-Risk Groups within Each CLIP Score

Patients within each CLIP score group were split according to whether they had low/high IGF-1. Within each CLIP or I-CLIP score, the estimated median overall survival for IGF-1-high patients was higher than the median overall survival for IGF-1-low patients. We observed strong trends that were not statistically significant in the scoring system groups (table 5). However, this was not surprising, given the extremely low power for detecting such differences given the small number of IGF-1-low subjects $(\leq 15)$ within all groups. However, our overall sign test that compared low and high IGF-1 groups and

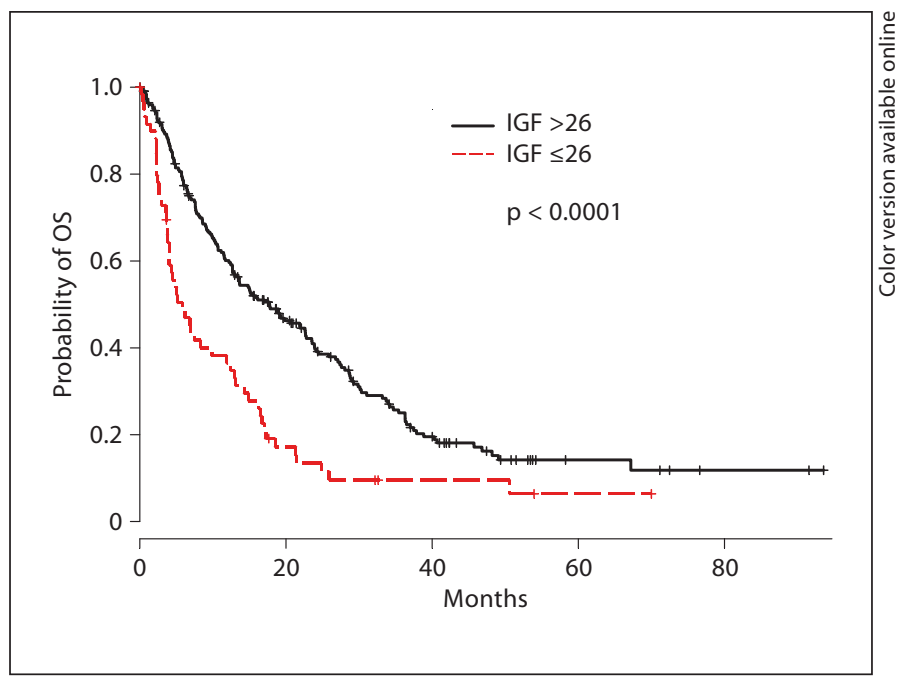

Fig. 1. Kaplan-Meier estimates of overall survival (OS).

assessed the prognostic information of IGF-1 was significant $(p=0.031)$. Therefore, our preliminary results indicated that the estimated median overall survival was greater in IGF-1-high patients within all groups, which contain independent patients, indicating that those patients within all scores tended to have better prognosis than IGF-1-low patients.

Our preliminary scoring system, named I-CLIP, integrates a dichotomized IGF-1 level into the CLIP score variables; score between 0 and 7 for each patient (table 6). Specifically, the I-CLIP scoring system was computed in the following way: CLIP score + IGF-1 score (1 if IGF $\leq 26$, and 0 if IGF $>26$ ). Based on the C-index analysis that compared the prognostic ability of the two systems, the concordance probabilities for CLIP and I-CLIP were 0.7037 and 0.7096 , respectively. U-statistics indicated that the differences in C-index were statistically significant $(\mathrm{p}<0.0001)$. Computing a 'partial' C-index using only subjects whose group membership changed between CLIP and I-CLIP (0.547 for CLIP, 0.617 for I-CLIP), we observed that the IGF-1-low subjects were better classified when moved into the next higher risk group by ICLIP. The calculated C-index for the V-CLIP (V = VEGF) score was 0.7041 , and the U-statistics $p$ value for I-CLIP versus V-CLIP was 0.056 . Figure 2 contains the KaplanMeier plots for the separate CLIP groups, and figure 3 contains the Kaplan-Meier plots for the separate I-CLIP groups. CLIP 4 and 5 were joined as one group (4+), and I-CLIP 4, 5 and 6 were joined as one group (4+). 
Table 5. Log-rank test on overall survival (OS) for CLIP groups split by IGF-1 (IGF-1 = 0 if IGF $>26$; IGF-1 = 1 if IGF $\leq 26$ )

\begin{tabular}{|c|c|c|c|c|c|c|c|}
\hline CLIP & Varname & Level & $\begin{array}{l}\text { Patients } \\
\mathrm{n}\end{array}$ & Event $^{\mathrm{a}}$ & $\begin{array}{l}\text { Median OS time } \\
\text { months }(95 \% \mathrm{CI})\end{array}$ & $\mathrm{p}$ & Power \\
\hline 0 & IGF-1 & $\begin{array}{l}\text { All patients } \\
0 \\
1\end{array}$ & $\begin{array}{r}54 \\
45 \\
9\end{array}$ & $\begin{array}{r}26 \\
21 \\
5\end{array}$ & $\begin{array}{c}36.49(28.73,67.2) \\
36.49(29, \mathrm{NA}) \\
21.4(6.84, \mathrm{NA})\end{array}$ & 0.5697 & 0.13 \\
\hline 1 & IGF-1 & $\begin{array}{l}\text { All patients } \\
0 \\
1\end{array}$ & $\begin{array}{r}80 \\
74 \\
6\end{array}$ & $\begin{array}{r}54 \\
49 \\
5\end{array}$ & $\begin{array}{l}22.65(17.85,34.19) \\
22.78(18.97,36.33) \\
16.88(16.31, \mathrm{NA})\end{array}$ & 0.2851 & 0.07 \\
\hline 2 & IGF-1 & $\begin{array}{l}\text { All patients } \\
0 \\
1\end{array}$ & $\begin{array}{l}77 \\
62 \\
15\end{array}$ & $\begin{array}{l}65 \\
51 \\
14\end{array}$ & $\begin{array}{r}12.2(9.83,15.52) \\
12.69(9.93,20.58) \\
8.35(5.06,17.1)\end{array}$ & 0.1386 & 0.24 \\
\hline 3 & IGF-1 & $\begin{array}{l}\text { All patients } \\
0 \\
1\end{array}$ & $\begin{array}{l}52 \\
38 \\
14\end{array}$ & $\begin{array}{l}48 \\
35 \\
13\end{array}$ & $\begin{array}{l}6.02(4.18,10.42) \\
7.68(5.85,12.69) \\
3.63(2.27, \mathrm{NA})\end{array}$ & 0.124 & 0.67 \\
\hline 4 & IGF-1 & $\begin{array}{l}\text { All patients } \\
0 \\
1\end{array}$ & $\begin{array}{r}19 \\
7 \\
12 \\
\end{array}$ & $\begin{array}{r}19 \\
7 \\
12 \\
\end{array}$ & $\begin{array}{l}2.37(2.14,12.46) \\
2.14(0.95, \mathrm{NA}) \\
3.17(2.3, \mathrm{NA})\end{array}$ & 0.9114 & 0.14 \\
\hline 5 & IGF-1 & $\begin{array}{l}\text { All patients } \\
0 \\
1\end{array}$ & $\begin{array}{l}6 \\
2 \\
4\end{array}$ & $\begin{array}{l}5 \\
1 \\
4\end{array}$ & $\begin{array}{l}2.66(2.37, \mathrm{NA}) \\
2.37 \text { (NA, NA) } \\
2.68(0.62, \mathrm{NA})\end{array}$ & 0.3508 & 0.09 \\
\hline
\end{tabular}

${ }^{\mathrm{a}}$ Event $=$ death.

Table 6. I-CLIP scoring system (0-7)

\begin{tabular}{|c|c|c|c|}
\hline \multirow[t]{2}{*}{ I-CLIP score variable } & \multicolumn{3}{|l|}{ Scores } \\
\hline & 0 & 1 & 2 \\
\hline Child-Pugh stage & A & $\mathrm{B}$ & $\mathrm{C}$ \\
\hline Tumor morphology & uninodular and $\leq 50 \%$ & multinodular and $\leq 50 \%$ & massive or $>50 \%$ \\
\hline AFP & $<400 \mathrm{ng} / \mathrm{ml}$ & $\geq 400 \mathrm{ng} / \mathrm{ml}$ & \\
\hline Portal vein thrombosis & no & yes & \\
\hline IGF-1 & $>26 \mathrm{ng} / \mathrm{ml}$ & $\leq 26 \mathrm{ng} / \mathrm{ml}$ & \\
\hline
\end{tabular}

Table 7. Multivariable Cox proportional hazards model for IV-CLIP: CLIP score variables + IGF-1 dichotomized by $26 \mathrm{ng} / \mathrm{ml}+$ VEGF dichotomized by $450 \mathrm{pg} / \mathrm{ml}$

\begin{tabular}{llccc}
\hline & IV-CLIP score variables & HR & 95\% CI of HR & p \\
\hline Child-Pugh & B vs. A & 1.69 & $1.22-2.33$ & 0.001 \\
Tumor morphology & C vs. A & 2.84 & $1.12-7.22$ & 0.03 \\
& 1 vs. 0 & 1.67 & $1.15-2.43$ & 0.007 \\
AFP & 2 vs. 0 & 3.65 & $2.46-5.42$ & $<0.0001$ \\
Portal thrombosis & $\geq 400$ vs. $<400 \mathrm{ng} / \mathrm{ml}$ & 1.72 & $1.26-2.34$ & 0.0006 \\
IGF-1 & yes vs. no & 1.41 & $0.89-2.23$ & 0.14 \\
VEGF & $\leq 26$ vs. $>26 \mathrm{ng} / \mathrm{ml}$ & 1.53 & $1.09-2.13$ & 0.01 \\
\hline
\end{tabular}




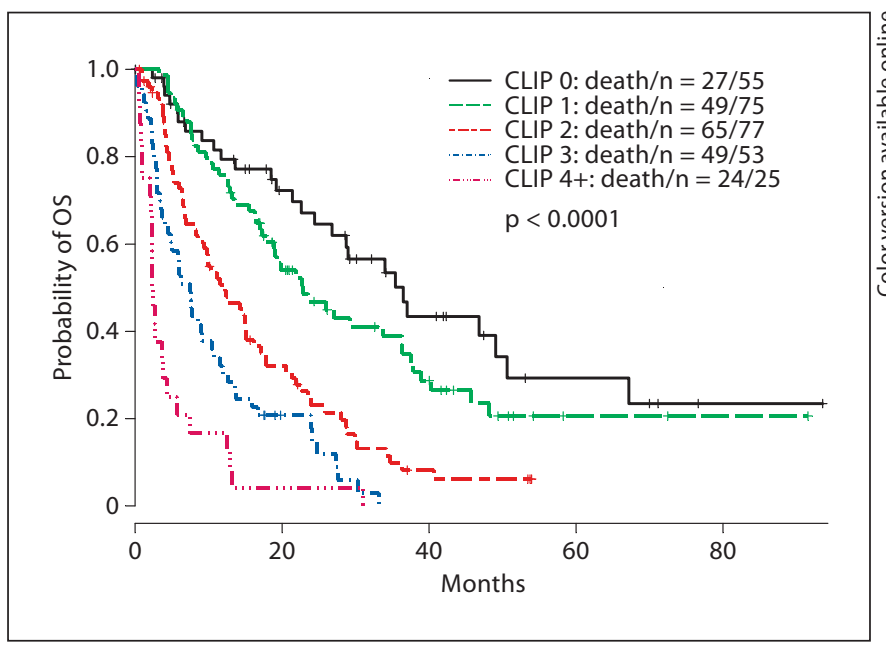

Fig. 2. Kaplan-Meier plots for CLIP groups. OS = Overall survival.

\section{Constructing an IV-CLIP Scoring System}

Our current multivariate analysis, using the dichotomized values of both biomarkers, indicated that IGF-1 and the VEGF were significant independent prognostic factors for overall survival, even after adjusting for CLIP parameters (for IGF-1: $\mathrm{p}=0.01$, HR 1.53, 95\% CI 1.092.13, and for VEGF: $\mathrm{p}=0.01$, HR 1.57, 95\% CI 1.12-2.22; table 7). We also observed that IGF-1 and VEGF incorporation into the CLIP score did not alter the HRs for the CLIP factors. However, the C-index analysis for IV-CLIP was 0.7092 , almost identical to that of the I-CLIP (0.7096).

\section{Discussion}

One of the major challenges in HCC management is prediction of survival and prognosis, given the marked heterogeneity noted in patients with HCC because of the two-disease state of CLD and HCC that independently affects their survival and prognosis. Our most recent study [12] introduced the V-CLIP score, integrating baseline plasma VEGF, as a marker that was shown in several studies to correlate with the tumor staging and invasiveness [27], into the CLIP score, and it showed significant improvement in prediction of survival. However, since accurate assessment of the status of the CLD is also essential to determine both short- and long-term prognosis and to make therapy decisions in patients with HCC, there is an unmet need for non-invasive liver reserve biomarkers to assess the severity of the CLD. Our current study aimed at evaluating the utility of plasma IGF-1

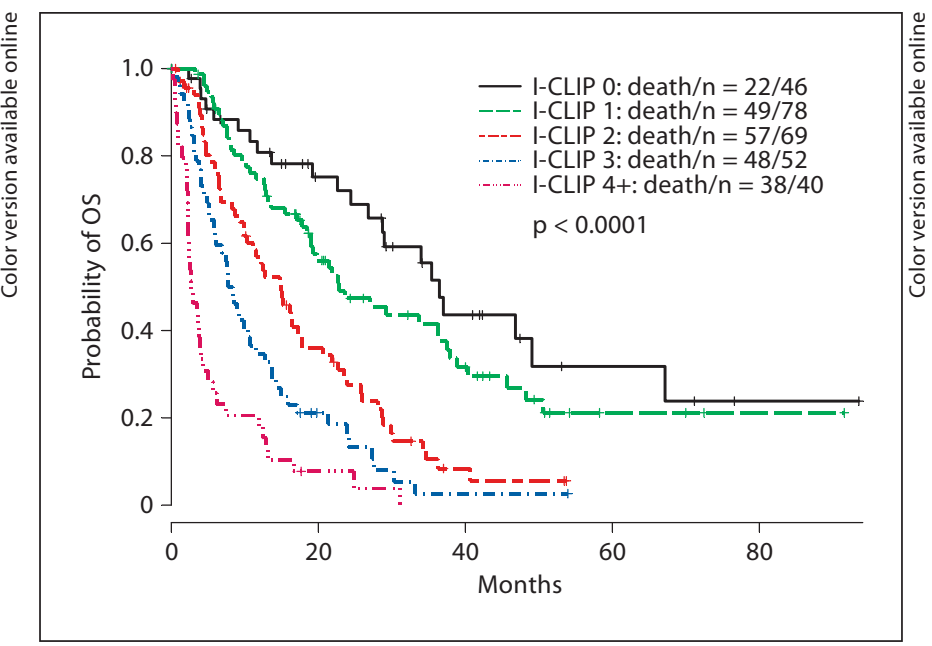

Fig. 3. Kaplan-Meier plots for I-CLIP groups. OS = Overall survival.

in this setting since it is synthesized mainly by the liver and significantly decreases in CLD and cirrhosis [19-22]. Therefore, our current score, I-CLIP, takes into account assessing a baseline plasma biomarker that is shown in our patient population to correlate with the CLD condition, using non-invasive molecular assays. Our combined clinical and laboratory index using plasma IGF-1 and parameters of the CLIP score is advantageous since it is easily calculated and could be replicated independently. Notably, the CLIP score validation in our patient population is consistent with prior studies of Western HCC patient populations. Notably, a substantial number of our patients had advanced BCLC stages B-D (239 patients, $82.9 \%)$. Therefore, the superiority of CLIP over BCLC in our advanced (or unresectable) HCC patient population, the standard clinical trials population, is also consistent with prior studies of patients with advanced HCC, since BCLC staging of this patient population is challenged. However, evaluating the incorporation of IGF-1 and other biologically pertinent biomarkers into BCLC staging of more diverse patient populations, in addition to evaluating other commonly used HCC staging systems, may prove useful in the assessment of HCC prognosis and hence in guiding the treatment decisions and patients' stratification in clinical trials. While none of these staging systems is yet approaching routine clinical use, rapid growth in plasma biomarkers assay technology may provide new avenues for non-invasive ways of assessing the severity of CLD and the biology of HCC tumors, and may prove beneficial after incorporation into the HCC staging systems to refine patients' stratification. 
Our study has some limitations. First, our study cutoff point was based on the recursive portioning method that identified the best cutoff point which correlated with the survival of our patient population; therefore, the IGF-1 cutoff point may differ in other patient populations. However, choosing an optimal cutoff point for plasma biomarkers in cancer research remains challenging in general, given the possible daily variations in the circulating levels and the potential effects of patients' genetics, nutritional status, gender, and age. Nevertheless, our results clearly indicate that the IGF-1 cutoff point we identified was independent of and complementary to our patients' clinicopathologic prognostic factors. Moreover, additional independent studies in other patient populations are warranted, not only to confirm our concept, but also to possibly help to identify an optimal range to be used in this setting. Additionally, we utilized the commercially available ELISA kits to measure plasma IGF-1 and VEGF. Although the methodology is reproducible in expert research facilities, the measurement should be done in a Clinical Laboratory Improvement Amendments (CLIA)-certified laboratory before using it in clinic to guide therapy decisions. Furthermore, while 394 HCC patients signed consent forms to participate in the study, baseline plasma samples were available for $288 \mathrm{pa}$ tients only. The main reason for missing blood samples collection was mainly related to insufficient time to obtain blood samples during the initial assessment in clinic. However, our analysis indicated that there were no major differences between both groups as aforementioned. Finally, our findings are based on a single institution experience and will need to be validated prospectively in other centers and patient populations. Furthermore, measuring IGF-1 carrier binding protein, IGFBP-3 and serum protease activity, the main determinants of the circulating level of IGF-1, may shed more light on the IGF-1 pathway in CLD and HCC, and will also confirm the utility of plasma IGF-1 in assessing the severity of the liver condition in CLD and HCC. Interestingly, recent studies of circulating IGF-1 in cancer patients [28-31] found that high IGF-1 level was associated with a higher risk of cancer. However, the goal of our current study was to evaluate the level of IGF-1, as a marker of the underlying synthetic function of the liver. Finally, the majority of our patient population had advanced unresectable disease. However, this population represents the classic patient population of the HCC clinical trials, who critically need new approaches to improve their prognostic stratification, which is crucial in comparing and interpreting trial results and also in decision making in clinical practice.

In conclusion, searching for new tools of assessment of the hepatic reserve in patients with HCC is essential to improving their prognostic stratification. This approach will directly affect therapy decisions, treatment outcome, and refine advanced HCC patients' stratification in clinical trials. Our study results indicate that lower baseline plasma level of IGF-1 correlated with advanced clinicopathologic parameters of patients with HCC. The integration of IGF-1 into the CLIP score (I-CLIP) significantly improved prognostic stratification of patients with advanced HCC. However, independent validation of our study is warranted.

\section{Acknowledgements}

The authors of the article would like to thank Dr. Karen Muller for editing the manuscript and Dr. John Heymach for helpful comments on the study. The study was supported by National Institutes of Health (NIH) RO3 grant ES11481, CA106458-01 (to M.H.), and by philanthropic funds to the Department of Gastrointestinal Medical Oncology.

\section{Disclosure Statement}

All authors have no commercial associations (e.g. consultancies, stock ownership, equity interests, patent-licensing arrangements, etc.) that might pose a conflict of interest in connection with the submitted article.
References
1 A new prognostic system for hepatocellular carcinoma: a retrospective study of $435 \mathrm{pa}$ tients: the Cancer of the Liver Italian Program (CLIP) investigators. Hepatology 1998; 28:751-755.

2 Llovet JM, Bru C, Bruix J: Prognosis of hepatocellular carcinoma: The BCLC staging classification. Semin Liver Dis 1999;19:329338.
- 3 Bruix J, Sherman M: Management of hepatocellular carcinoma. Hepatology 2005;42: 1208-1236.

-4 Bruix J, Sherman M, Llovet JM, Beaugrand M, Lencioni R, Burroughs AK, Christensen E, Pagliaro L, Colombo M, Rodes J: Clinical management of hepatocellular carcinoma. Conclusions of the Barcelona-2000 EASL conference. European Association for the Study of the Liver. J Hepatol 2001;35:421-430. 
5 Kaseb AO, Hassan MM, Lin E, Xiao L, Kumar V, Pathak P, Lozano R, Rashid A, Abbruzzese JL, Morris JS: V-CLIP: integrating plasma vascular endothelial growth factor into a new scoring system to stratify patients with advanced hepatocellular carcinoma for clinical trials. Cancer 2011;117:2478-2485.

6 Mirici-Cappa F, Gramenzi A, Santi V, Zambruni A, Di Micoli A, Frigerio M, Maraldi F, Di Nolfo MA, Del Poggio P, Benvegnu L, Rapaccini G, Farinati F, Zoli M, Borzio F, Giannini EG, Caturelli E, Bernardi M, Trevisani F: Treatments for hepatocellular carcinoma in elderly patients are as effective as in younger patients: a 20-year multicentre experience. Gut 2010;59:387-396.

$\checkmark 7$ Prospective validation of the CLIP score: a new prognostic system for patients with cirrhosis and hepatocellular carcinoma. The Cancer of the Liver Italian Program (CLIP) investigators. Hepatology 2000;31:840845.

8 Farinati F, Rinaldi M, Gianni S, Naccarato R: How should patients with hepatocellular carcinoma be staged? Validation of a new prognostic system. Cancer 2000;89:22662273.

$>9$ Levy I, Sherman M: Staging of hepatocellular carcinoma: assessment of the CLIP, Okuda, and Child-Pugh staging systems in a cohort of 257 patients in Toronto. Gut 2002;50:881885.

10 Ueno S, Tanabe G, Sako K, Hiwaki T, Hokotate H, Fukukura Y, Baba Y, Imamura Y, Aikou T: Discrimination value of the new western prognostic system (CLIP score) for hepatocellular carcinoma in 662 Japanese patients. Cancer of the Liver Italian Program. Hepatology 2001;34:529-534.

-11 Llovet JM, Bruix J: Prospective validation of the Cancer of the Liver Italian Program (CLIP) score: a new prognostic system for patients with cirrhosis and hepatocellular carcinoma. Hepatology 2000;32:679-680.

12 Chan SL, Mo FK, Johnson PJ, Liem GS, Chan TC, Poon MC, Ma BB, Leung TW, Lai PB, Chan AT, Mok TS, Yeo W: Prospective validation of the Chinese University Prognostic Index and comparison with other staging systems for hepatocellular carcinoma in an Asian population. J Gastroenterol Hepatol 2011;26:340-347.
13 Tsai AL, Burke CT, Kennedy AS, Moore DT, Mauro MA, Dixon RD, Stavas JM, Bernard SA, Khandani AH, O’Neil BH: Use of yttrium-90 microspheres in patients with advanced hepatocellular carcinoma and portal vein thrombosis. J Vasc Interv Radiol 2010; 21:1377-1384.

$\checkmark 14$ Hsu CH, Yang TS, Hsu C, Toh HC, Epstein RJ, Hsiao LT, Chen PJ, Lin ZZ, Chao TY, Cheng AL: Efficacy and tolerability of bevacizumab plus capecitabine as first-line therapy in patients with advanced hepatocellular carcinoma. Br J Cancer 2010;102:981986.

15 Dhanasekaran R, Kooby DA, Staley CA, Kauh JS, Khanna V, Kim HS: Prognostic factors for survival in patients with unresectable hepatocellular carcinoma undergoing chemoembolization with doxorubicin drugeluting beads: a preliminary study. $\mathrm{HPB}(\mathrm{Ox}-$ ford) 2010;12:174-180.

-16 Hsu CY, Hsia CY, Huang YH, Su CW, Lin HC, Lee PC, Loong CC, Chiang JH, Huo TI, Lee SD: Selecting an optimal staging system for hepatocellular carcinoma: Comparison of 5 currently used prognostic models. Cancer 2010;116:3006-3014.

17 Huitzil-Melendez FD, Capanu M, O’Reilly EM, Duffy A, Gansukh B, Saltz LL, AbouAlfa GK: Advanced hepatocellular carcinoma: which staging systems best predict prognosis? J Clin Oncol 2010;28:2889-2895.

18 Daughaday WH: The possible autocrine/ paracrine and endocrine roles of insulin-like growth factors of human tumors. Endocrinology 1990;127:1-4.

19 Buzzelli G, Dattolo P, Pinzani M, Brocchi A, Romano S, Gentilini P: Circulating growth hormone and insulin-like growth factor-I in nonalcoholic liver cirrhosis with or without superimposed hepatocarcinoma: evidence of an altered circadian rhythm. Am J Gastroenterol 1993;88:1744-1748.

-20 Luo SM, Tan WM, Deng WX, Zhuang SM, Luo JW: Expression of albumin, IGF-1, IGFBP-3 in tumor tissues and adjacent nontumor tissues of hepatocellular carcinoma patients with cirrhosis. World J Gastroenterol 2005; 11:4272-4276.

21 Su TS, Liu WY, Han SH, Jansen M, Yang-Fen TL, P'Eng FK, Chou CK: Transcripts of the insulin-like growth factors I and II in human hepatoma. Cancer Res 1989;49:1773-1777.
22 Stuver SO, Kuper H, Tzonou A, Lagiou P, Spanos E, Hsieh CC, Mantzoros C, Trichopoulos D: Insulin-like growth factor 1 in hepatocellular carcinoma and metastatic liver cancer in men. Int J Cancer 2000;87:118-121.

$23 \mathrm{Su}$ WW, Lee KT, Yeh YT, Soon MS, Wang CL, Yu ML, Wang SN: Association of circulating insulin-like growth factor 1 with hepatocellular carcinoma: one cross-sectional correlation study. J Clin Lab Anal 2010;24:195-200.

24 Elsammak MY, Amin GM, Khalil GM, Ragab WS, Abaza MM: Possible contribution of serum activin A and IGF-1 in the development of hepatocellular carcinoma in Egyptian patients suffering from combined hepatitis $C$ virus infection and hepatic schistosomiasis. Clin Biochem 2006;39:623-629.

-25 Garcia-Galiano D, Sanchez-Garrido MA, Espejo I, Montero JL, Costan G, Marchal T, Membrives A, Gallardo-Valverde JM, Munoz-Castaneda JR, Arevalo E, De la Mata M, Muntane J: Il-6 and IGF-1 are independent prognostic factors of liver steatosis and nonalcoholic steatohepatitis in morbidly obese patients. Obes Surg 2007;17:493-503.

26 Harrell FE CR, Pryor DB, Lee KL, Rosati RA: Evaluating the yield of medical tests. JAMA 1982;247:2543-2546.

27 Kaseb AO, Hanbali A, Cotant M, Hassan MM, Wollner I, Philip PA: Vascular endothelial growth factor in the management of hepatocellular carcinoma: a review of literature. Cancer 2009;115:4895-4906.

28 Chan JM, Stampfer MJ, Giovannucci E, Gann PH, Ma J, Wilkinson P, Hennekens $\mathrm{CH}$, Pollak M: Plasma insulin-like growth factor-I and prostate cancer risk: a prospective study. Science 1998;279:563-566

29 Hankinson SE, Willett WC, Colditz GA, Hunter DJ, Michaud DS, Deroo B, Rosner B, Speizer FE, Pollak M: Circulating concentrations of insulin-like growth factor-I and risk of breast cancer. Lancet 1998;351:1393-1396.

30 Ma J, Pollak MN, Giovannucci E, Chan JM, Tao Y, Hennekens CH, Stampfer MJ: Prospective study of colorectal cancer risk in men and plasma levels of insulin-like growth factor (IGF)-I and IGF-binding protein-3. J Natl Cancer Inst 1999;91:620-625.

>31 Yu H, Spitz MR, Mistry J, Gu J, Hong WK, Wu X: Plasma levels of insulin-like growth factor-I and lung cancer risk: a case-control analysis. J Natl Cancer Inst 1999;91:151-156. 